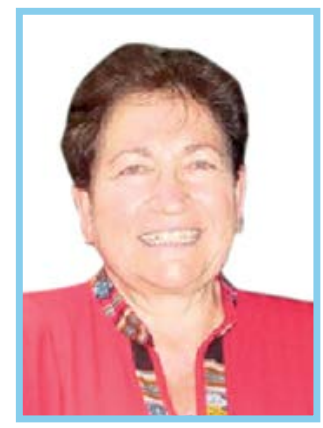

Mg. Isabel García Ruiz

\title{
LA EDUCACIÓN \\ Y LA MUJER, \\ FECUNDIDAD \\ EDUCATIVA
}

\section{RESUMEN}

La educación es una cuestión vital una y una segunda creación. Así como para nacer hace falta la mujer y la madre, para una segunda creación, es imprescindible una mujer educadora. Educadora fecunda que saque lo mejor de sus educandos en y para el siglo XXI, usando el mejor de los métodos "el amor que enseña a enseñar"; a través de saber leer, se descubren los gestos personales, los acontecimientos sociales y las otras caras de las cosas; $y$ saberse atenerse a ello.

\section{ABSTRACT}

The present article considers that woman is and educator by nature, dream to be a mother, providing to their children, to their students, milk and honey, therefore, takes its educational role convinced that she is doing in each student a "second creation". The author also considers the parent education of women is the "pedagogy of love teaching teach".

\section{PALABRAS CLAVE}

Mujer educadora, segunda creación, lectura, amor, fecundidad.

\section{KEYWORDS}

Women educator, pedagogy of love, teaching teach.
$\mathrm{H}$ ay razones muy bellas para colaborar en el número extraordinario de esta Revista, sobretodo, en este tiempo especial de los 50 años de la Facultad, motivo de la celebración de los Cincuenta Años de la prestigiosa Universidad Femenina del Sagrado Corazón - UNIFÉ, de Lima, Perú. La conozco desde hace muchos años, amigas entrañables se han formado en ella y, además, dos de mis amores se unen a estas efemérides: el amor a la educación y el amor a Perú.

Quiero contemplar la Educación como un mosaico gigante. Todo aporte, por muy humilde y sencillo que sea, puede considerarse como una tesela pequeña pero significativa. Sin la que el mosaico quedaría algo incompleto.

Recuerdo que aprendí pronto a leer, a descifrar signos: signos-letras, signos-acontecimientos, signos-sentimientos, signos-relaciones... Aprendí también a interpretarlos, a valorarlos y a darles mi visión particular, y, sobre todo, a aplicarlos en la vida y en el aula.

Confieso que nací vocacionada para la educación y, desde que aprendí a leer, palabra clave en la vida y en la Educación, las personas y las cosas se me revelaron en clave de lectura educativa; más aun desde aquel día inolvidable en el que aparecí en el aula y cuarenta niñas me esperaban expectantes, sus caras, sus manos pasando las hojas del libro, sujetando el cuaderno, agarrando el lápiz, con sus miradas lectoras y sus silencios. Me decían que esperaban mucho de mí y que no debía defraudarlas. 
Fue mi familia la primera clave de interpretación lectora, con su seguridad forjada recíprocamente por la experiencia del mutuo amor y, más tarde, mi maestra de primaria, una mujer serena y admirable que sabía educar con su sola presencia.

Un día, mi maestra me sorprendió mirando fijamente el crucifijo de la clase y me dijo: "si miras fijamente algo con afecto acabas por conocerlo y, a su vez, te devuelve su mirada, amorosa y creativa, descubriendo y sacando de ti lo mejor". Algo así, pensé, como si me llamara continuamente a la existencia, me bendijera y me recreara. Me prometí mirar así, más tarde, a mis alumnas.

He leído mucho, obras de maestros excelentes por sus obras maestras. La tesela educativa que hoy aporto es el resultado de la interiorización e integración de aquello que recibí de cada lectura, de cada mirada, fraguado y asimilado personalmente por lo singular de cada ser, lo que lo hace irrepetible.

\section{LA EDUCACIÓN Y LA MUJER, FECUNDIDAD EDUCATIVA}

Puede educar una familia, una aldea, una tribu, un pueblo, un país... pero quien no puede nunca dejar de educar es la mujer tanto dentro del hogar como en el colegio y en la Universidad. Esta afirmación la quiero fundamentar en dos definiciones.

La primera es la propia etimología de la palabra educar. Educare: educar, criar, alimentar... y educere, mediante el prefijo ex- "sacar fuera" y el verbo ducere, "guiar", 'conducir'. Cuando se habla de "sacar fuera", se evoca, en un primer momento, la escena del parto, la imagen de la mujer, el proceso del embarazo, la dulzura, la emoción, la espera y la esperanza... Si nos fijamos en "guiar", "formar", nos vienen a la mente los primeros pasos, las correcciones amorosas... ipuede haber alguien con más recursos antropológicos para emplearlos en el reto educativo que la mujer? iexiste otro ser más capacitado para sacar lo mejor de sí y de otros?

Precisamente por sus componentes antropológicos, la mujer, suficientemente instruida y preparada, está llamada, especialmente, a ser educadora, para guiar y conducir y formar; para sacar fuera, desde dentro, las potencialidades y capacidades innatas, que no es atiborrar y llenar la cabeza, de fuera a dentro, con informaciones trasnochadas o con datos que se obtienen, on line...

El proceso educativo multifacético y multiaxial, necesita, a lo largo del camino y de la edad, la transmisión de técnicas de base concisas y, sobre todo, de saberes, criterios, valores, actitudes, costumbres y testimonios del bien vivir y del mejor actuar; requiere, a la vez, promover el desarrollo de la persona, de sus capacidades intelectuales y morales según la edad y las circunstancias particulares, familiares y sociales de cada educando. Esta cosmovisión educativa, tan extensa en calidad y cantidad, no sería óptima si se dejara solamente a la responsabilidad de una sola mujer, o de un solo educador.

Pero cuando se trata de sentar las bases de todos los aprendizajes mencionados, es decir, cuando se trata de educar niños y adolescentes, nadie más adecuado que la mujer para iniciar el proceso. La mujer es más intuitiva para descubrir necesidades particulares y formas personalizadas para satisfacerlas. Su paciencia es proverbial, su ternura indiscutible, el calor de su cercanía imprescindible, su sensibilidad puede captar el futuro y el pasado del educando con un solo golpe de vista certero y perspicaz... más aún, cabría decir, que lo verdaderamente germinal y nuclear, como si de un embarazo se tratara, como si de dar a luz se pidiera, solo se ve bien, solo se hace bien, desde el corazón de una mujer.

La segunda definición, "La educación, en su acepción más clara, puede considerarse como una Segunda Creación". A la que José Gras añade, "la 
educación es la cuestión más vital del mundo porque no hay operación en la esfera de la actividad humana que no la presuponga como base o móvil".

"Cuestión vital", referida a la educación y "segunda creación" como su definición, tienen su fundamento en las palabras de Jesús de Nazaret a Nicodemo, "hay que nacer de nuevo" y en otra frase del Nuevo Testamento "he aquí que hago nuevas todas las cosas". Pero la intuición profética de José Gras, abre un panorama que podría considerarse un nuevo paradigma educativo: la educación, segunda creación, por los caminos del descubrimiento de la verdad y del entrenamiento en el bien.

La Educación, "segunda creación”, imita la obra creadora de Dios cuando trabaja por moldear al educando, una y otra vez, para poner en acto todas sus potencialidades; es como volver a nacer y nadie mejor que la figura de la madre, de la mujer, con su instinto nato, para descubrir el alcance de la definición y mostrar los caminos de su desarrollo, su metodología y sus etapas.

El P. Gras considera a la mujer, por estas razones, "primera educadora", pues es en el seno de la familia, especialmente en el regazo de la madre, donde el niño, el adolescente y el joven quedan marcados por lo que sienten, reciben, perciben, intuyen, ven y oyen. El joven, con estos nutrientes en sus edades tempranas, llega a la Universidad con seguridad y autoestima, garantía para la consecución de los objetivos de la educación superior.

De aquí se deduce que hay que preparar a la mujer, madre y educadora, para desempeñar una gran misión en la época presente y más aún en el futuro. Formarla intelectualmente para que sea competente en las distintas esferas del saber y en las nuevas tecnologías, en las mejores y más humanas pedagogías; es decir, un desarrollo integral y completo que la lleve a la acción educativa decidida a hacer, de la realidad de cada educando, una criatura nueva.
La sociedad necesita el rol de la mujer educadora, hoy más que ayer, pues bien se dice que el siglo XXI es el siglo de la mujer. Su influjo será más evidente, la vida más rica y armónica gracias a la inteligencia emocional de la mujer ofrecida y ejercida en las diversas instancias sociales. Es bueno, por tanto, seguir diciendo la importancia de educar a la mujer, aunque parezca obvio. Una mujer educada es la mejor educadora. Para que tenga temple moral y gran sapiencia, pues la mujer instruida puede influir visiblemente en la salvación de la sociedad y conseguir grandes triunfos, gracias a la suavidad y amor de su cercanía, curando heridas y desvaneciendo errores.

Retomando la definición, segunda creación, y evocando la primera, aparece en nuestro panorama educativo la figura de Eva; no he pensado nunca que pudo haber sido perdición para la raza humana la primera mujer, madre de todos; personalmente creo, opinión discutible, que fue la impulsora de abrir pasos a la humanización, a salir de la instintividad animal e inocencia primaria para dar pasos en cumplimiento del mandato divino: Creced, multiplicaosydominadla tierradelaquesalisteis. Hoy, la mujer, enaltecida por Jesús de Nazaret y ganando terreno en reconocimiento cultural y capacitación profesional, es instrumento glorioso de una espléndida renovación social. Pues, cuando una sociedad vive un cambio de época, cambio de paradigmas y de imaginario educativo, y se encuentra deshecha en algunos de sus aspectos, la mujer puede hacer sentir, en la familia y en el país, la dulzura de los valores fundamentales de su identidad patria, trazar caminos de amor y felicidad y abrir caminos de restauración. Este nuevo paradigma social indica que hay que cambiar, pero no dice qué cambios precisos requiere. Humildemente, hemos de estar en tanteos y búsquedas.

Hay que contar también con los datos que en los jóvenes arroja la Postmodernidad. Son muchos los estudios ya realizados, análisis y estadísticas 
de diverso calado. Añado una pequeña reflexión fijándome, solamente, en el prefijo "post”. El joven post-moderno no tiene claro lo que quiere, lo que tiene claro es que no quiere lo anterior, con lo que se tambalean las antiguas coordenadas. Parecía que la salvación estaba en la razón, la metafísica, los descubrimientos de las ciencias, las tecnologías... ¿No será un reto que nos lanzan a ayudarles a descubrir lo que realmente quieren? Conversando este tema con otros educadores, se nos ocurrió si sería bueno sacar a la luz aspectos últimamente olvidados, tales como la fuerza de la naturaleza, el ser en su aspecto de gratuidad, la experiencia de la fenomenología, el silencio, la belleza, la poesía, la búsqueda del espíritu y la trascendencia. Supondría asumir el reto de recrear, humanizar, espiritualizar a las personas de nuestros educandos.

Re-crear es posible, aún con las limitaciones de su teoría, Carl Roger dice: "El individuo posee en sí mismo potenciales recursos para su propia comprensión, para cambiar su auto concepto, sus actitudes y para dirigir su conducta, estos recursos pueden ser liberados a condición de que un determinado clima de actitudes psicológicas facilitadoras pueda ser logrado."

También nos ofrece Erich Fromm un aporte iluminador: "La tierra prometida (la tierra es siempre un simbolo femenino y materno) se describe como plena de leche y miel. La leche es el símbolo del primer aspecto del amor, el de cuidado y afirmación. La miel simboliza la dulzura de la vida, el amor por ella y por estar vivos. La mayoría de las madres son capaces de dar leche, pero solo unas pocas son capaces de dar miel también. Para estar en condiciones de dar miel, una madre debe ser no solo una buena madre, sino una persona feliz -y no son muchas las que logran alcanzar esa meta. No hay peligro de exagerar el afecto sobre el niño, el amor de la madre a la vida es contagioso. Ejerce un profundo efecto sobre la personalidad total del niño; indudablemente, es posible distinguir entre los niños -y los adultos- los que recibieron leche y los que recibieron leche y miel".

La mujer que sabe dar leche y miel, además de "primera educadora", es también dignificadora de la persona humana. Tiene en cuenta, en su actividad pedagógica, la dignidad de cada educando, los re-crea en el respeto a su propia dignidad y le proporciona las herramientas necesarias de las relaciones, pues no puede haber educación si no hay encuentro de personas que se dignifican mutuamente:

> Relaciones intrapersonales: aprender a tratarse a sí mismos, a conocerse, a valorarse y a quererse. Conocer lo que hace, cómo lo hace y lo que debe hacer y cómo mejorar sus recursos. Si no aprendió esto desde niño ni de adolescente, hay que enseñarle en la Universidad, antes, durante y después de la enseñanza de las materias curriculares.

> Relaciones interpersonales: El educando se conoce, está capacitado para conocer a los demás y para descubrir la necesidad de que otra persona le descubra sus zonas desconocidas, y reciba de ella la parte que no sabe intuir por sí solo. Se abrirá al grupo y recibirá sus riquezas; surgirá el agradecimiento, la confianza y la solidaridad.

> Relaciones intrasociales: Aprender de sí mismo y del pequeño grupo a conocer el contexto, más allá y más acá de cada lugar, tiempo, condición y edad. Conocerse en la aldea global, no para diluirse y desidentificarse, sino para sabernos hermanos con la identidad común de ser personas, pasajeros de la misma nave espacial por rutas inexploradas, en busca de aventuras nuevas y al encuentro de tesoros increíbles para todos.

La Educación tiene como instrumento primordial el saber leer. También en esto tiene la mujer un papel fundamental y muy acertadamente podríamos decir de ella que es casa de lectura.

La Lectura es ícono de la belleza, de ella surge una fragancia que llega a ser cualidad personal; leer y gozar llega a ser una ciencia que se aprende mejor al calor de una mujer. Es la gran aliada de la 
educación escolar, universitaria y de la educación permanente. Saber leer libros, es poseer la mejor guía, sean libros impresos o digitales; leer cosas, acontecimientos, situaciones, comunicaciones, relaciones, leer los signos de los espacios y de los tiempos.

Saber interpretar signos. Signos gráficos, esbozados, dibujados, pintados, soñados; signos sonoros, oídos, escuchados, emitidos, pronunciados, cantados; signos personalizados, interiorizados, apropiados, evocados, expresados, criticados, valorados, evaluados, proyectados... re-cordados. Todo un reto educativo, saber leer, enseñar a leer, enseñar a aprender a leer.

La lectura, instrumento "vital", para saber leerse y leer a los demás; leer, necesidades, sentimientos, emociones, sonrisas, miradas... hasta lo invisible, los mundos inéditos y la otra cara de las cosas; leer gestos, visibles o subliminales. Y, aplicados a cada situación concreta, personal, familiar, política, económica, laboral, sabiendo distinguir en cualquier información, discurso político o cultural, la cara oculta de las palabras, la verdad de la mentira, la autenticidad de la demagogia.

Será por eso que la Universidad de Harvard exige para ingresar, matemáticas, comprensión lectora y expresión escrita, porque, añade, enseñar a leer es superior a impartir competencias trasnochadas.

Lecturatiene un panorama espiral,ampliándose y completándose constantemente. Así como el acto de educar es espiral y, de dentro a fuera, abriéndose, así el aprendizaje de la lectura:

> Inmanente, desde dentro, escuchando los sonidos ancestrales, el "érase una vez".

> Permanente, aquíy ahora, en la realidad concreta, con todas las ventanas abiertas para otear lo que puede ser y soñarlo... "será así una vez".

> Trascendente, captadora de las energías del pasado y del futuro, desde lo que hoy conocemos y lo que no conocemos, desde la verdad descubierta y la Verdad por descubrir, hasta ver lo invisible, "más y mejor que ayer y menos que mañana".

Saber leer exige siempre más; está entrenándose hasta el virtuosismo, como la declamación de un poema, la interpretación de una partitura, de una danza, de un ritual, siempre "in crecendo"; con el arte de quien enseña y el arte de quien aprende y despertando el arte mejor, dormido, quizás, "del salón en el ángulo oscuro, de su dueño, tal vez, olvidado"

Una segunda creación a través del criterio pedagógico del amor. "Para enseñar y educar niños es preciso amarles; nada como el amor contribuye a dar con todos los resortes que más poderosamente los mueve. El amor enseña a enseñar. El amor ennoblece y perfecciona al profesor y hace buenos a los estudiantes... El cariño religioso es el que emplean como su principal auxiliar las Hijas de Cristo Rey". La educación de las educaciones es aquella que eleva todos los rectos y nobles sentimientos.

El amor a la educación y a los jóvenes requiere actitudes heroicas en los educadores. "Para educar con éxito a los niños y jóvenes, conviene suavizar la voz"; el amor mueve a la actualización de métodos, a abrirse a las redes y a las nuevas tecnologías, a saber discernir su uso.

El amor proporciona la mejor formación intelectual de las múltiples inteligencias, desarrolla el razonamiento lógico, crítico y emocional; el amor enriquece el desarrollo de la imaginación, la creatividad y la afectividad. Saber hacer una evaluación crítica de las redes sociales y de su influencia.

Hay que descartar programas, planes y proyectos no adecuados a la realidad social ni a los jóvenes actuales deben ser considerados como una verdadera "constelación de jóvenes", por la diversidad de actitudes y formas de vida. 
El amor sabe irrumpir ciencia en la cultura juvenil, diversa y fragmentada, que nos ha deparado el postmodernismo. Educa y ama personalizadamente.

El amor se esfuerza por hacer la educación amable, fácil y alegre y traza un sistema preventivo que evite las faltas, lleva a decir lo que se debe y no se debe hacer, con novedad y creatividad y despierta la atención, el interés y la alegría. "Cuando estamos alegres, no debemos pedirnos permiso para ello con la reflexión de si a todas horas tenemos permiso para estarlo. No hay nada que tenga una recompensa más segura que la alegría; en ella la recompensa y la acción son una misma cosa. Quien está alegre siempre tiene motivo para ello, justamente el de estar alegre".

El amor hace educadores que sueñan formas inéditas y personales y moldean un ser educado único e irrepetible, dueño de sí y a la misma altura de sus semejantes.

El amor cuenta con toda la tribu, para hacer triunfar la Educación-Verdad y la EducaciónVirtud. Este espíritu, movido por el amor, proporciona una segunda piel, una sensibilidad propia y contagiosa que acrecienta el BIEN personal y social y brinda un testimonio de vida, es coherente entre lo que dice y hace, prepara para el inevitable sufrimiento ayudando a "flotar" por encima del dolor.

\section{IMPLICACIONES EDUCATIVAS PARA LA SOCIEDAD PERUANA}

Es bueno leer detenidamente el Informe "Necesidades educativas del Perú", año 2008. La exposición de necesidades es clara y están bien definidas. Mi reflexión al respecto es que hay que tenerlas presentes, añadiendo las nuevas necesidades surgidas en estos cinco últimos años y aportando, además, lo escrito en el presente artículo y los que me sugieren los años vividos en Perú como educadora de niñas y jóvenes, y como orientadora en la formación permanente de las educadoras del Colegio Cristo Rey. Pueblo Libre, Lima.

Hay una imagen de la mitología Inca que siempre me impresionó, la Pacha Mama, Diosa de la tierra y de la fertilidad agrícola, así es la mujer peruana, su personificación hasta hoy. La mujer peruana sigue siendo la diosa de la fertilidad, la mujer madre, la educadora para la mayor fecundidad y fertilidad. Ella puede transformar la sociedad peruana y hacer de cada ciudadano una persona educada. Ella puede hacer en cada ciudadano una "segunda creación", sacar a la luz lo mejor de sus ancestros y lo mejor de todos los siglos de su historia. Ella puede enseñarle el tipo de lectura propuesta para que no se deje "engañar" ante los falsos discursos y sepa leer, entre líneas, los renglones torcidos de las intenciones egoístas, lejanas del bien común.

En muchas empresas, no todavía en las instancias educativas, se está aplicando el trabajo teledirigido $\mathrm{y}$, al parecer con éxito y grandes ahorros. En educación no sabemos qué sucederá. No hemos de estar cerrados a nada, pero sí hay que garantizar esos espacios sagrados de contacto personal y de socialización.

Contacto humano para la humanización, así podría resumir el aporte que me brindaron y enseñaron las peruanas y peruanos que me aman y a los que amo entrañablemente. Esta riqueza no debe perderla la sociedad del Perú, ni en este siglo ni en los venideros.

\section{CONCLUSIONES}

La mujer educadora está llamada a cuidar la vida, creando un ambiente rico en valores, favoreciendo la alegría y el sentido positivo de la vida. La mujer es educadora por su misma naturaleza, soñada para ser madre, que proporciona a sus hijos, a sus alumnos, leche $y$ miel. Realiza su función educativa convencida de que está haciendo en cada educando una "segunda creación". 
La pedagogía matriz de la mujer es la "pedagogía del amor que enseña a enseñar". El amor la ilumina, anima y le da fuerzas para hacer personas alegres y felices. Por ello, está al día de los mejores proyectos, programaciones y metodologías.
La mujer educadora no deja nunca de analizar su trabajo educativo, buscando personal y grupalmente, la mejor metodología para una eficaz evaluación. No deja nunca de mirar a sus educandos, leyendo amorosamente su proceso para reorientarlo, convencida de que la educación, si es dada con amor, enriquece la vida y el alma de las personas.

\section{REFERENCIAS}

Gras, José. Pensamiento Educativo de las Religiosas Hijas de Cristo Rey.

Gras, José (1870). Una cuestión que parece pequeña, fundamento de las actuales grandes.

Juan, 3,6 .

Apocalipsis, 21,5a . http://www.elpsicoasesor.com/201l/09/las-tresactitudes-basicas-de-la.html

Fromm, Erich. El Arte de amar.

Schonpenhauer, Arthur. El Arte de ser feliz. 